\title{
Mrs. Michelle Obama
}

\author{
Hazel Marie Harris Watson
}

Sweet daughter of the universe...sent into our midst

To caress the earth with your compassionate, gentle nature

Mother Earth smiled at the first woman of African descent to be the First Lady of the United States of America ... it's forty-fourth, First Lady An educated woman, bold of step, with a captivating smile and eyes filled with wonder and awe...

Mother earth sent a woman not afraid to show emotions in the face of catastrophe and pain...

A woman whose compassionate heart allowed her gracious, gentle hands to reach out and touch the wounded and grieving with empathy ...unashamed ...

A true humanitarian, a gardener, the perfect hostess, an exercise enthusiast, a dancer, a TV star...

Mother Earth sent a First Mother, who made the children of America feel loved and each one became a Superstar ...whenever they came into her presence...

Mother Earth looked down on America so in need of Grace ...

And sent us a true Earth Mother full of grace, charm, and elegance...Mrs. Michelle Obama

H. M. H. Watson $(\bowtie)$

Freeport Memorial Library Memoir Group, AARP, Westerville, OH, USA

(C) The Author(s) 2018

M. Duster et al. (eds.), Michelle Obama's Impact

on African American Women and Girls,

https://doi.org/10.1007/978-3-319-92468-7_9 